\title{
Informal Networking and Industrial Life Cycles
}

by

\author{
Andreas Pyka \\ November 1998 \\ University of Augsburg \\ Faculty of Economics
}

Universitätsstr. 16, D-86135 Augsburg, Tel. +49-821-598-4179, Fax: +49-821-598-4229

E-Mail: andreas.pyka@wiso.uni-augsburg.de

JEL: O31, O33, L2

Key-words: technological spillovers, informal networks, industrial life cycle

\section{Introduction}

Modern industrial development processes of new technologies are characterized by an increasing complexity and interdependence of the different actors combining different knowledge assets. Today, hardly any innovation can be assigned to one specific technological field. Also, the sciences are becoming increasingly differentiated and specialized, thus enhancing the necessity of horizontal and vertical knowledge transfer between the actors of innovation processes. In this context, where single actors and even single firms are unable to keep pace with technological progress, the idea of collective invention becomes obvious.

Concerning this, two points emphasized by modern innovation theory are of importance: First, the overwhelming significance of cross-fertilization-effects are recognized (e.g. Mokyr, 1990). In a technological development inevitably confronted with bottlenecks, new developmental potentials can be created (- in the first place -) by the amalgamation of different technologies. 
Second, these technological interdependencies are mediated mainly by technological spillovers, which are no longer a natural feature of technological know-how. The knowledgebased approach of modern innovation theory makes firm specificities as well as a technology specifities responsible for an only curtailed unavoidable emergence of spillovers. However, these positive externalities are a widely-spread phenomenon and claim for an economic explanation.

Informal networks, i.e. loose relationships between firms, as well as between scientists and engineers are identified as an industrial organizational device, in which new technological knowledge is freely shared and distributed, and which can be considered as an important source of spillover effects (Freeman, 1991). However, within the neoclassical approach, if recognized at all, this behaviour apparently is at odds with myopic self-interest and can only be explained in highly artificial and ad hoc ways (Silverberg, 1988). Therefore, in modern innovation theory other approaches are invoked, allowing to model informal networks to develop as collective phenomena. In particular, the theory of self-organization seems to be appropriate in order to allow for only procedural rational agents, which in a cumulative and path-dependent process constitute cooperative or non-cooperative environments (Pyka, 1997). In this modeling framework the institutions of informal networks can self-organize as emergent properties in dependence of the technological intensity of firms' surroundings as well as on critical fluctuations which in a way represent the feature of intrinsic uncertainty of innovation processes.

In this paper the basic modeling framework of the evolution of informal networks is combined with some stylized facts of the time patterns of the industrial evolution sketched by the theory of industry life cycles. Integrating time-independent transition rates excludes the possibility of analytical solutions, so numerical simulation experiments have to be performed. The results of these experiments show structural developments at least qualitatively according to the predictions of life cycle theory. Most unexpectedly - from a traditional point of view - large informal networks as a potential source of technological spillovers can sometimes be observed in a state of the industry life cycle where $R \& D$ endeavours of firms are assumed to be already concentrated on exploiting scale economies and process technologies instead of exploring new technological opportunities. 
The paper is organized as follows: In the second part the theoretical framework of informal networks in an industry life cycle context is discussed. Part 3 deals with the formal structure of the self-organization approach to model informal networks and some first analytical results. In part 4 we simulate the respective system in order to integrate time patterns of the willingness to cooperate. The final part 5 finishes the discussion with some conclusions.

\section{Informal Networks in an Industrial Life Cycle Context}

Modern technical solutions are increasingly characterized by an interrelatedness between heterogeneous actors and knowledge fields. According to Joly and Mangematin (1995) two reasons are mainly responsible for this growing complexity of innovation processes: On the one hand the sheer number of different material inputs required for innovation and production has increased immensely. On the other hand, also the number of knowledge fields and skills necessary for innovation and production is growing steadily. No single firm can keep pace with the development of all relevant technologies. Therefore, firms must have access to external knowledge sources. This is even more important at early phases of the technological development, where technological uncertainty as well as financial constraints of new start-up companies face innovative actors with severe difficulties and contingencies. Informal networks or cooperative environments are an important organizational device for external learning, helping firms to cope with this growing complexity.

\section{- Technological uncertainty}

The search for new technologies is a risky and uncertain endeavour. This uncertainty intrinsic to the innovation process - does not allow either to predict the timing, nor the technological features nor the economic consequences of innovations: on the one hand, firms try to find new technological solutions for their production processes with ex-ante not anticipated consequences; on the other hand, new unforeseen and unexpected discoveries external to a firm may change the current situation. Thus, firms' decisions including their behaviour to exchange know-how cannot be described in a neoclassical optimization context but are to be seen as bounded rational. 
The development space within which firms learn and which firms attempt to explore consists of a broad set of technological opportunities providing potentials for progress. Here several regularities can be observed. First, the developmental potential of a specific technology is increasingly exhausted with progress on the respective technological trajectory. So-called intensive technological opportunities (Coombs (1988)) are becoming depleted step by step. By this technological as well as scientific boundaries come into effect more and more making further improvements increasingly difficult and sometimes even impossible to achieve.

Second, besides intensive opportunities characterizing a specific technology there are also extensive technological opportunities which arise out of cross-fertilization among different technologies (Mokyr (1990)). Here, new technical solutions are often actively initiated by firms which then generate new opportunities by the combination of already existing technologies. Sometimes the amalgamation of different - ex-ante considered as unrelated technologies leads to totally new technological fields; mechatronic or bionic are points in case. These structural tensions (Dahmén (1989)) between complementary technologies are an important prerequisite providing firms with an incentive to behave cooperatively, i.e. exchange their knowledge in order to get access to external knowledge sources.

Such technological interdependencies and their combining effect arise from different sources: Besides new ideas and findings in academia the manifold effects between up- and downstream productions among firms within and between industries are potential sources of such crossfertilization. These mutual influences come into effect mainly by technological spillovers.

\section{-Technological spillovers and appropriability}

Spillover effects arise whenever new technological know-how is not a purely private good and thus not entirely appropriable by the innovating firm. ${ }^{1}$ Imperfect appropriability conditions are responsible for inventors realistically anticipating that they will receive less than the maximum benefits arising out of an innovation. However, for two reasons modern innovation theory states that knowledge is only a latent public good. On the one hand, the capabilities of firms are not perfect so that they cannot simply draw back on any kind of often firm-specific external knowledge. On the other hand, technological knowledge has a local character caused by the technological specificities of different technological approaches. In mainstream

\footnotetext{
${ }^{1}$ See e.g. Winter, S. G. (1989).
} 
economics - modelling homogeneous agents and single innovation processes - the supposed public good character of new know-how is the main reason for an incentive to behave defectively and the firms' endeavours to keep their new knowledge secret. New innovation theory does not deny this but also emphasizes the idea-creating features of knowledge spillovers in the context of heterogeneous agents and different complementary and substitutive innovation activities.

Therefore, it is necessary to know whether these spillovers are only caused by imperfect appropriability conditions or whether they are actively initiated by firms. In other words, are they unplanned spillovers (Chesnais (1996)) going hand in hand with defective effects or purposefully initiated organizational devices? In the following, it will be argued that a prominent source of these spillovers are informal networks where firms voluntarily exchange new know-how in order to explore new extensive technological opportunities.

\section{-Informal networks}

The necessity to draw back on external knowledge sources has stimulated new mechanisms of collective action. Besides formal forms, such as R\&D joint-ventures or the establishing of technological standards, they include more informal practices, such as reverse engineering, and information exchange networks among engineers and scientists ${ }^{2}$. Reverse engineering means the involuntary leakage of new technical information, whereas informal communication in networks can be understood as a voluntary information exchange. Von Hippel (1989) introduced the concept of informal know-how trading and found empirical evidence for this in several industries. Informal know-how trading is the voluntary exchange of technical information and could be interpreted as a process of actively initiating technological spillovers. Nelson (1988, p. 318) states in this respect: "However, in some cases firms take positive actions to make their proprietary knowledge available to others". These new inter-firm-learning activities signal the changing nature of the technological progress and the declined ability of single actors to struggle alone with complexity.

What are the reasons for these knowledge-networks? Why do firms show cooperative attitudes? Informal networking can lead to positive sum games in the innovation activities of

\footnotetext{
${ }^{2}$ See Foray (1995).
} 
firms participating in the respective networks ${ }^{3}$. Besides an improved capability to meet the requirements for adaptations due to evolving technologies and improving the efficiency in times of change, the firms expect synergistic benefits. The amalgamation of different knowledge fields often results in the creation of something totally new, helping all involved actors to overcome technological constraints. To realize these synergistic benefits it is not sufficient to only know what the others are doing, but the firms even need to know how the respective technologies function and work together. And, for this inter-firm learning of often long-ranged cumulative, tacit and specialized know-how, a stable and long lasting cooperative environment is necessary ${ }^{4}$. Clark and Juma (1987, p.85) introduced the notion of evolutionary articulation characterized with an essentially resonating feature: "In order to achieve the status of useful knowledge it [the information flow] needs to undergo a process of evolutionary articulation between supplier and recipient." In a complex innovation process, networks are in a way a new institutionalized type of industrial organization ${ }^{5}$, capable of dealing better with this learning under high know-how requirements. Informal networking is an important mechanism for innovation diffusion and therefore an essential factor for enabling technical progress ${ }^{6}$.

These learning possibilities are a strong motive to behave cooperatively, which trade-off the opening up of extensive opportunities, and the acquisition of knowledge against potential losses due to cheating and opportunism ${ }^{7}$. The increasing complexity of technological knowhow forces firms to seek access to external knowledge sources with the important consequence that they also have to be such an external knowledge source in a broader context. Through the knowledge exchange processes a stable cooperative environment can be created. According to the respective share of cooperative attitudes, this increases the chance of a realization of surplus.

\section{-Informal networking and the industrial life cycle}

\footnotetext{
3 Dodgson (1994), p. 286 speaks of the improved ability to deal with complexity.

4 Kodama, F. (1992),"... technology fusion grows out of long term R\&D-ties with a variety of companies across many different industries."

${ }^{5}$ For Witt (1997) an institution develops with regularities in behaviour which are shown up regularly in similar situations.

${ }^{6}$ See Zuscovitch/Justman (1995).

${ }^{7}$ See Mody (1993).
} 
In the literature the emergence of informal networks is often combined with technological uncertainty. ${ }^{8}$ In a survey about reasons for innovation networks between firms, Dodgson (1993, p. 44) states ,... within this technological perspective, a key feature stimulating collaboration is uncertainty about technological development and diffusion. Since Schumpeter, many analyses of technical change have emphasized the discontinuous nature of innovation, and the problem this poses for firms." E.g. the paradigm/trajectory-framework ${ }^{9}$ directly associates the discontinuous nature of the innovation process with the role of uncertainty. While during the early phases of the creation of a new paradigm one is confronted with severe uncertainty, those contingencies decrease with further development and exhaustion of the specific technological opportunities. ${ }^{10}$ Besides this, investigations of industry life cycles (e.g. Klepper and Graddy (1990), Klepper (1997), Klepper and Simons (1997) and Utterback (1987)) have shown that in the early phases of new industries, which are mostly congruent to the emergence of a new technological paradigm, the market more or less is divided into small- and medium-sized firms. However, these Schumpeterian creative entrepreneurs (Schumpeter (1912)) are restricted in their possibilities to finance expensive research projects. One possibility to surmount financial bottlenecks is the collective pushing forward of technological progress and the exploration of new extensive opportunities via knowledge exchange in informal networks.

However, due to success-breeds-success effects, the most successful firms will increasingly grow while less successful firms are threatened by exit from the market. This leads to a concentration process - only a few but large firms will finally rule the respective market. „Implicitly, this involves a process whereby success breeds success, so that successful firms take over greater share of the market over time, leading to greater concentration." (Klepper, (1997, p. 151)).

\footnotetext{
${ }^{8}$ See Granstrand/Sjolander (1990) and Freeman (1991).

${ }^{9}$ See Dosi (1988), p. 1134.

10 "I suggest that, in general, innovative search is characterized with strong uncertainty. This applies, in primis to those phases of technical change that could be called preparadigmatic: During these highly exploratory periods one faces a double uncertainty regarding both the practical outcomes of the innovative search and also the scientific and technological principles and the problem solving procedures on which technological advance could be based. When a technological paradigm is established, it brings with it a reduction of uncertainty, in the sense, that it focuses the directions of search and forms the grounds of formating technological and market expectations more surely." Dosi (1988), p.1134.
} 
In the sense of Schumpeter (1943), these large enterprises are now less confronted with financial constraints in pushing ahead their specific research projects. On the one hand, they can more easily raise the necessary $R \& D$ budgets, on the other hand, at later stages of the technological development, technological opportunities are almost depleted directing the research endeavours more to incremental and less expensive technological improvements and the exploitation of scale economies. Thus, their willingness to behave cooperatively and share an informal network by generously making public new know-how is certainly decreasing.

\section{Informal Networks in a Synergetic Framework}

In the following we will introduce a theoretical approach to model the evolution of informal networks which also allows for the consideration of the time patterns most likely to occur in an industrial life cycle context. In contrast to neoclassical modelling our synergetic approach avoids the restrictive assumptions of perfect information and rationality by focusing on the routinized character of firm behaviour and the institutional character of innovation networks. In particular this approach focuses on self-organizational features in the evolution of informal networks by explicitly considering the effect of the macro-environment i.e. the institutional character of an informal network.

First, the basic structure of the model and an analytical solution will be outlined before we show some numerical simulations which become necessary when time-dependent transition rates are included.

\subsection{The Basic Structure of the Model}

First we have to introduce a population of $N$ firms which all are engaged in R\&D. These firms are deciding in every period whether to behave according to a cooperative attitude ' $c$ ' and disclose - at least partly - their new knowledge, or behave non-cooperatively ' $n c$ ' by avoiding the leaking out of their new R\&D results. The number of firms behaving cooperatively is $N_{l}$, non-cooperative firms are counted by $N_{2}$ respectively, accordingly $N=N_{1}+N_{2}$. Additionally, we 
need a variable $\tilde{N}, \tilde{N} \in[-N / 2 ; N / 2]$, which shows the absolute deviation from an equal distribution of both strategies $\left(N_{1}=N_{2}\right)$ :

(1) $\tilde{N}=N_{1}-N / 2=N / 2-N_{2} ; \tilde{N} \in \frac{N}{2} ; \frac{N}{2}$

Fig. 1 schematically shows the state-space: on the left side we find a totally non-cooperative environment $\tilde{N}=-N / 2$ where all firms apply a strategy of secrecy; accordingly, the right side represents an informal network including all firms $\tilde{N}=N / 2$. In-between states represent the respective distributions of actors with cooperative and non-cooperative strategies. The applied algorithm - the master-equation - describes the continuous development of this discrete statespace $\tilde{N}$ by computing the probability $P(\tilde{N} ; t)$ to meet a certain state in the course of time.

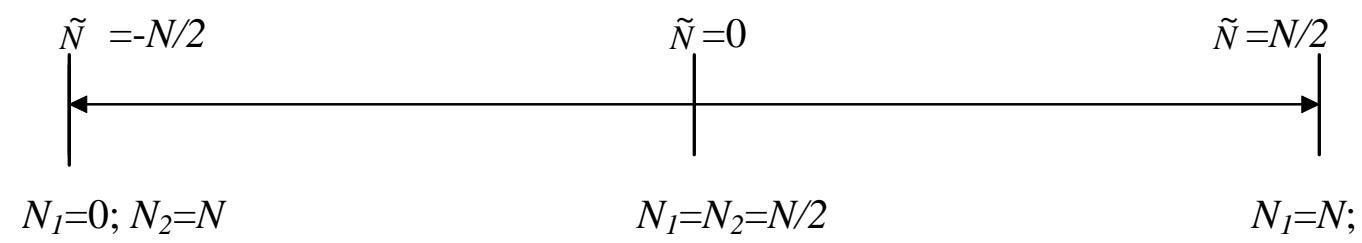

Fig. 1: state-space

What are the determinants of firm behaviour? To answer this question we have to introduce the individual transition rates, the core element of a master-equation. First, consider the incentives to change behaviour of an original non-cooperative firm along the state-space. A non-cooperative firm can join the informal network at any point in time $(n c \rightarrow c)$. The firm is influenced in its decision by the prevailing macrostructure $P(\tilde{N} ; t)$ - the either cooperative or non-cooperative environment. Concerning the latter, the firm feels only a low pressure to change its strategy and behave cooperatively. The probability of finding complementary know-how in a likewise small informal network is small. However, the possibility of crossfertilization effects grows with the size of the informal cooperation for two reasons: on the one hand, with a growing number of cooperative firms the quantity of the spillover pool also grows. On the other hand, at least in the short run, the quality of spillovers also increases with increasing heterogeneity of the firms participating in the network. With growing quantity and quality, the probability of combining seemingly inconsistent ideas increases. And the missing 
know-how to detect the beneficial dynamic synergies is captured by this originally defective firm entering the network.

To represent this formally we use a simple linear relationship

$$
i_{n c \rightarrow c}=\beta \cdot \tilde{N} ; \beta>0 .
$$

The incentive to join the informal network $i_{n c \rightarrow c}$ increases with increasing network size. The parameter $\beta$ represents the intensity of $\mathrm{R} \& \mathrm{D}$ endeavours. A larger $\beta$ value means a growing intensity of technology. This could also be interpreted as $\beta$ representing technological uncertainty whereby we refer to the assumption - often found in the literature - that with increasing R\&D intensity technological uncertainty increases also.

We assume that the advantages of the cooperative strategy are the disadvantages of the noncooperative strategy and vice versa; therefore transition rates are symmetric. In an overall noncooperative environment the pressure to change the cooperative attitude $(c \rightarrow n c)$ and behave defectively is likewise large. On the one hand, the potential disadvantages of falling behind by disclosing one's own knowledge, and the non-cooperative behaviour of others, has to be considered. On the other hand, the probability of finding complementary know-how and realizing the beneficial effects of the extensive opportunities is quite small in a more or less defective environment. But the incentive to behave defectively $i_{c \rightarrow n c}$ decreases in an increasingly cooperative environment. To represent this, formally we get

(3) $i_{c \rightarrow n c}=-\beta \cdot \tilde{N}$.

Finally, we have to consider the time-dependence of the willingness of firms to cooperate. It is argued below that in early phases of the technological development firms are more likely willing to exchange their know-how due to technological as well as financial constraints. However, this cooperative attitude decreases on later stages of the technology life cycle when the exploitation of scale economies and incremental innovations are in the centre of interest. Formally, we consider this time-dependence of the willingness to cooperate by including a time-preference function $\delta(t)$ in the transition rates. In the most simple case we suppose a linear relationship of the preference function with respect to the industry life cycle: 


$$
\delta(t)=\delta_{0}-r \cdot t, \quad \delta_{0}, r>0
$$

where $\delta_{0}$ represents the preference for cooperation at the beginning and $r$ represents the rate of reduction in the course of time.

Drawing back on the elements above we get the following transition rates (5) describing the probability to switch to the cooperative strategy if initially non-cooperative and (6) vice versa:

$$
\begin{aligned}
& p_{n c \rightarrow c}(\tilde{N})=\alpha \cdot \exp [\beta \cdot \tilde{N}+\delta(t)], \\
& p_{c \rightarrow n c}(\tilde{N})=\alpha \cdot \exp \{-[\beta \cdot \tilde{N}+\delta(t)]\},
\end{aligned}
$$

where $\alpha$ is a scaling parameter. This exponential formulation usually found in the literature for transition rates has a twofold effect: First it normalizes the respective values to the positive area, as is necessary because of representing transition probabilities. This exponential formulation further ensures the effect of short-term self-enhancing and wide range attenuation. ${ }^{11}$ At first, the growing network size supports the beneficial effects of the cooperative environment. But in the long run there are two reasons for an attenuation of this effect. On the one hand, there is a growing probability that the firms in the network have already realized the opportunities another firm outside the network can offer. On the other hand, the heterogeneity of firms in the network decreases because they will become technologically closer by sharing their know-how. ${ }^{12}$ However, heterogeneity is a necessary precondition for a high information content of spillovers.

With these transition rates we can now formulate the master equation (7) describing the evolution of informal networks

$$
\begin{aligned}
\frac{d P(\tilde{N} ; t)}{d t} & =q_{n c \rightarrow c}(\tilde{N}-1) \cdot P(\tilde{N}-1 ; t)+q_{c \rightarrow n c}(\tilde{N}+1) \cdot P(\tilde{N}+1 ; t) \\
& -\quad q_{n c \rightarrow c}(\tilde{N}) \cdot P(\tilde{N} ; t)-q_{c \rightarrow n c}(\tilde{N}) \cdot P(\tilde{N} ; t) .
\end{aligned}
$$

\footnotetext{
${ }^{11}$ See Eger and Weise (1995) and Gierer (1981).

12 Dodgson (1996), p. 67: „If firms in a network share knowledge over a longer period, then they will increasingly come to resemble one another with detrimental consequences for novelty and innovation."
} 
where we used so-called total transition probabilities $q_{n c \rightarrow c}$ and $q_{c \rightarrow n c}$ describing the aggregate behaviour

$$
\begin{aligned}
& q_{n c \rightarrow c}(\tilde{N})=N_{2} \cdot p_{n c \rightarrow c}(\tilde{N})=\left(\frac{N}{2}-\tilde{N}\right) \cdot p_{n c \rightarrow c}(\tilde{N}) \text { and } \\
& q_{c \rightarrow n c}(\tilde{N})=N_{1} \cdot p_{c \rightarrow n c}(\tilde{N})=\left(\tilde{N}+\frac{N}{2}\right) \cdot p_{c \rightarrow n c}(\tilde{N}) .
\end{aligned}
$$

The first two terms on the r.h.s. of the master-equation (7) indicate the probability flows from neighbour states into the state $\tilde{N}$, whereas the other two terms describe the flows which leave the respective state. The master equation can therefore be interpreted as a kind of profit and loss account of a single state.

\subsection{The Analytical Treatment of the System}

Time-dependent transition rates do not allow for an analytical solvability of our system. Therefore, we first ignore this time dependency by neglecting (4) and show some useful analytical features of our master-equation describing the evolution of informal networks. Following Weidlich and Haag (1983) we can transform our discrete state space to a continuous one by introducing the variable $x$ :

$$
x=2\left(n_{1}-0.5\right)=-2\left(n_{2}-0.5\right), x \in[-1 ; 1]
$$

which describes the whole population as relative shares of cooperative $\left(n_{l}=N_{l} / N\right)$ and noncooperative $\left(n_{2}=N_{2} / N\right)$ firms. For time-independent total transition rates we get:

(11) $\quad \tilde{q}_{n c \rightarrow c}(x)=\left(\frac{1}{2}-\frac{x}{2}\right) \cdot \alpha \cdot \exp (\tilde{\beta} \cdot x)$ and

(12) $\quad \tilde{q}_{c \rightarrow n c}(x)=\left(\frac{x}{2}+\frac{1}{2}\right) \cdot \alpha \cdot \exp [-(\tilde{\beta} \cdot x)]$ where $\tilde{\beta}=\beta \cdot N$ 
and $K(x)$ is the so called drift-coefficient ${ }^{13}$, which strikes the balance between both possible directions of change:

$$
K(x)=\tilde{q}_{n c \rightarrow c}(x)-\tilde{q}_{c \rightarrow n c}(x) .
$$

By integrating this drift-coefficient over the state space we get the potential function $V(x)$

$$
\begin{aligned}
V(x) & =\mathbb{Z}_{-1}^{1} \mathbb{Z}(x) d x \\
& ={\underset{-1}{1} \boldsymbol{Z}}_{2} \alpha[\sinh (\tilde{\beta} x)-x \cdot \cosh (\tilde{\beta} x)] d x \\
& =\frac{2 \alpha}{\tilde{\beta}^{2}} \cdot[\tilde{\beta} \cdot x \cdot \sinh (\tilde{\beta} x)-(1+\tilde{\beta}) \cdot \cosh (\tilde{\beta} x)]+\text { const } .
\end{aligned}
$$

This potential function can be used to derive an implicit picture of the development in the course of time without explicitly considering time $t .{ }^{14}$ Resting points of a potential function are the respective minima, which cannot be left without an exogenous impulse. They represent so-called stationary solutions in which the development of the system's macro-structure has come to rest and only minor and balanced fluctuations on the micro-structure will occur. In fig. 2 we see the potential function for different values of the technological intensity $\beta$.

$v(x)$

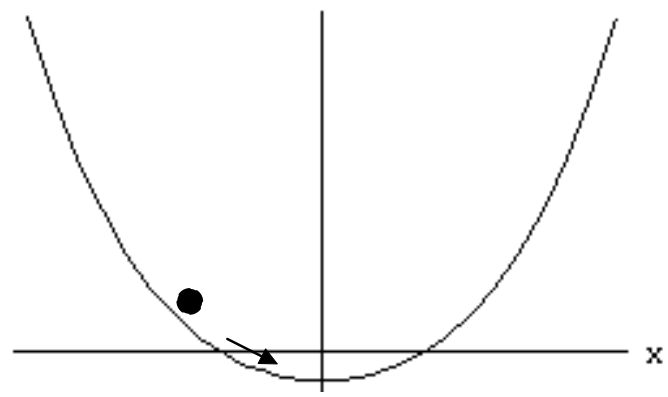

fig. 2a) $\beta=0.8$

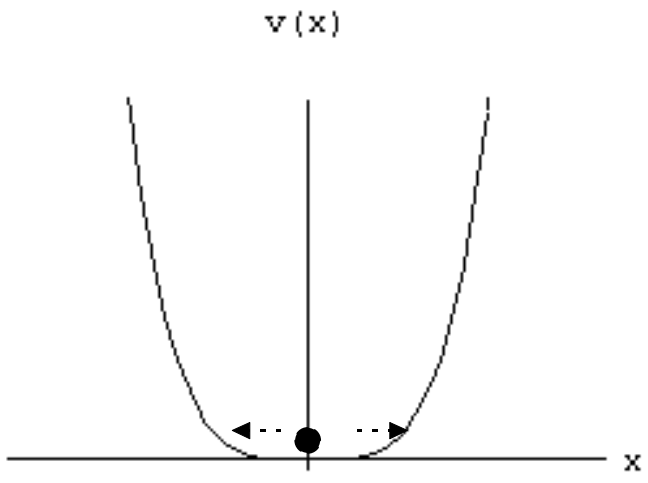

fig. 2b) $\beta=1$

\footnotetext{
${ }^{13}$ Weidlich/Haag (1983), p. 23.

14 See Erdmann (1993), pp. 27-3.
} 


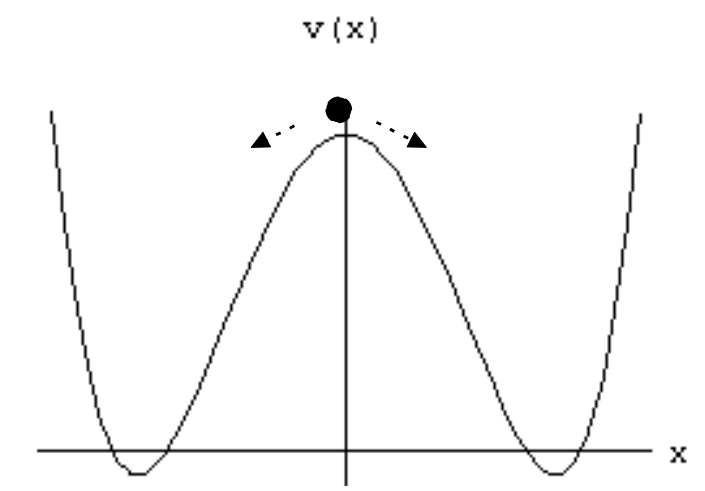

fig. 2c) $\beta=1.25$

The resting-point context is expressed by the black marble which come to a standstill in the attraction of an equilibrium at the bottom of the potential function. In the case of low technological intensity $(\beta=0.8)$ shown in fig. $2 a)$ we find a unequivocal solution where the probability to find either a cooperative or a non-cooperative firm equals 0.5 . So here, the firms are divided into two same-sized groups, one acting cooperatively, the other defectively. In an environment where technology is not of major importance, the effect of short-term selfenhancing and wide range attenuation is responsible for the by and large neglecting of the possibility of a larger informal network because of the likely technological resemblance caused by an exchange of know-how.

In the second scenario we increase technology intensity $(\beta=1.0)$. The black marble does not stop here in an unequivocal minimum but rolls around in a quite flat valley of the potential function. Responsible for this is a significant decrease of the effect of the wide range attenuation. Higher technological intensity leads to slower depletion of the potentials of crossfertilization. Therefore, firms do not resemble each other in the same way as above, the exploration of new extensive opportunities becomes more likely even at more advanced phases of the technological trajectory. We find here a somewhat fuzzy solution including higher probabilities for larger non-cooperative environments as well as larger informal networks.

In the third scenario we increase technological intensity even further. With respect to the previous scenarios we find a totally changed development. Here, two different possible solutions can be clearly discriminated. The valley of the potential function into which the black marble will fall cannot be predicted but depends on critical fluctuations during the phase transition the system undergoes. There is a local minimum for a solution where defective 
behaviour dominates. Here, despite the requirements of collective invention no larger network formation seems to be possible. But this minimum is not global; on the other, more cooperative side of the graph a second local minimum can be found. This solution describes a large informal network, where the respective cooperative firms at least partly share their technological know-how and large technological spillovers are actively initiated. Here, besides the short-term self-enhancing feature, a long-run positive impact additionally makes the original solution unstable and leads to a new bimodal distribution of cooperative and noncooperative firms. The formation of informal networks with a firm strategy of actively initiating spillovers is as probable as the formation of isolated firms with more traditional defective attitudes towards the impact of technological spillovers.

\section{Simulating the Evolution of Informal Networks}

After these first analytical insights of the system we now include the time-dependence of the willingness to cooperate (4) into the transition rates supposed to occur in an industry life cycle context. In the case of time-dependent transition rates no longer any conclusion can be made by drawing back on potential functions; for the analysis of the evolution of informal networks numerical simulations of the respective system becomes unavoidable. Now, a stationary solution expressed by the minimum(a) of the potential function no longer exists, any specific developments taken place are continuously threatened by a changing environment maintaining the system's dynamics.

In a first simulation we again investigate a scenario with a low technology intensity $(\beta=0.8)$. Starting with an egalitarian distribution of cooperative and non-cooperative firms $P\left(N_{l}=N_{2} ; 0\right)=1$ we get the development shown in figure 3a. Additionally, so-called density plots (fig. 3b) are pictured which show the development of the peak of the probability distributions in the course of time. 


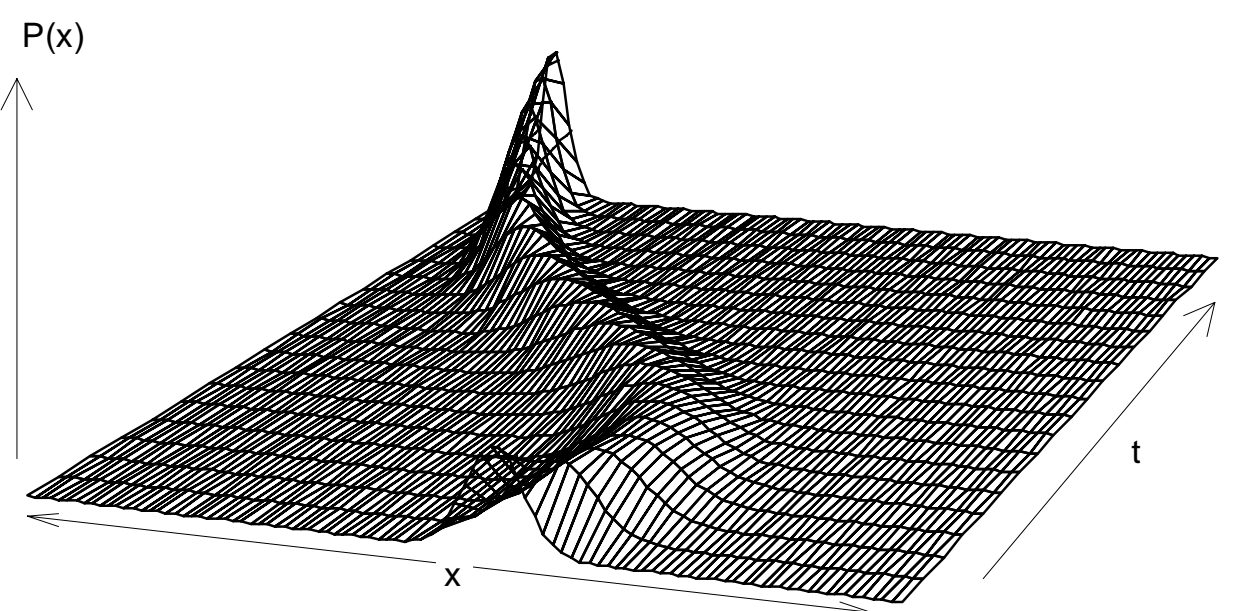

fig. 3a) Probability distribution of scenario I $\left(\beta=0.8, \delta_{0}=0.25, r=0.0005\right)$

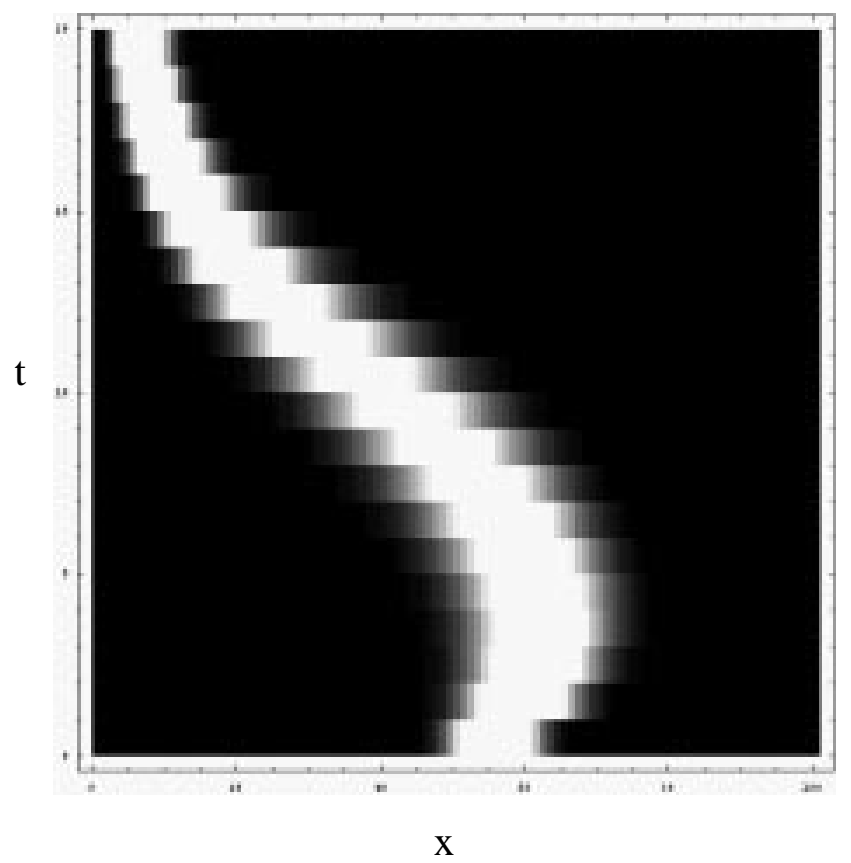

fig. 3b) Density plot of scenario I ( $\beta=0.8, \delta_{0}=0.25, r=0.0005$ )

Despite a low technological intensity, at the beginning of the industry life cycle we find a clear bias in the direction of larger informal networks which can be entirely traced back to the inclusion of the preference function. In the course of time the willingness to cooperate steadily decreases, following the preference function which continuously shifts towards defective behaviour. Accordingly, the probability of informal networks decreases in the course of the industry-life-cycle, firms try to keep their new know-how secret which more and more prevents larger spillover pools. In this scenario we do not find any unexpected consequences due to the original basic willingness to cooperate. At the end of the outlined development the preference for cooperation in the transition rates is so low that the probability to find firms engaged in informal know-how-exchange is almost zero. 
Are there any changes to be expected if we switch to a scenario with a higher technological intensity? The second simulation describes the system's development with $\beta=1.5$ shown in figure 4.

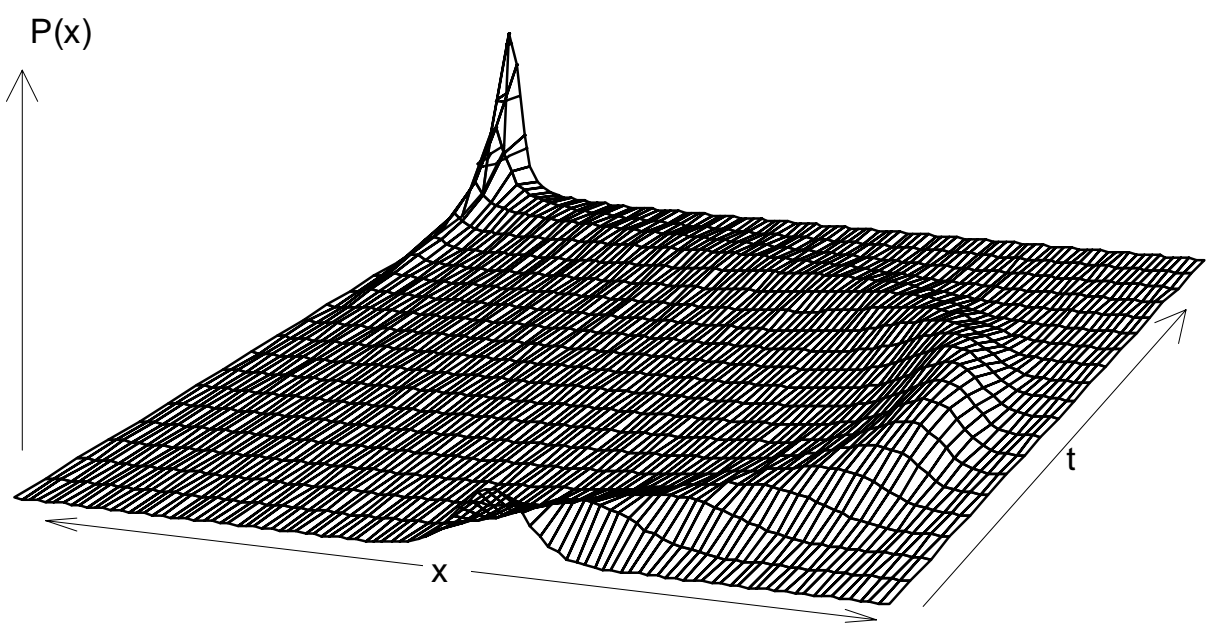

fig. 4a) Probability distribution of scenario II $\left(\beta=1.5, \delta_{0}=0.25, r=-0.0005\right)$

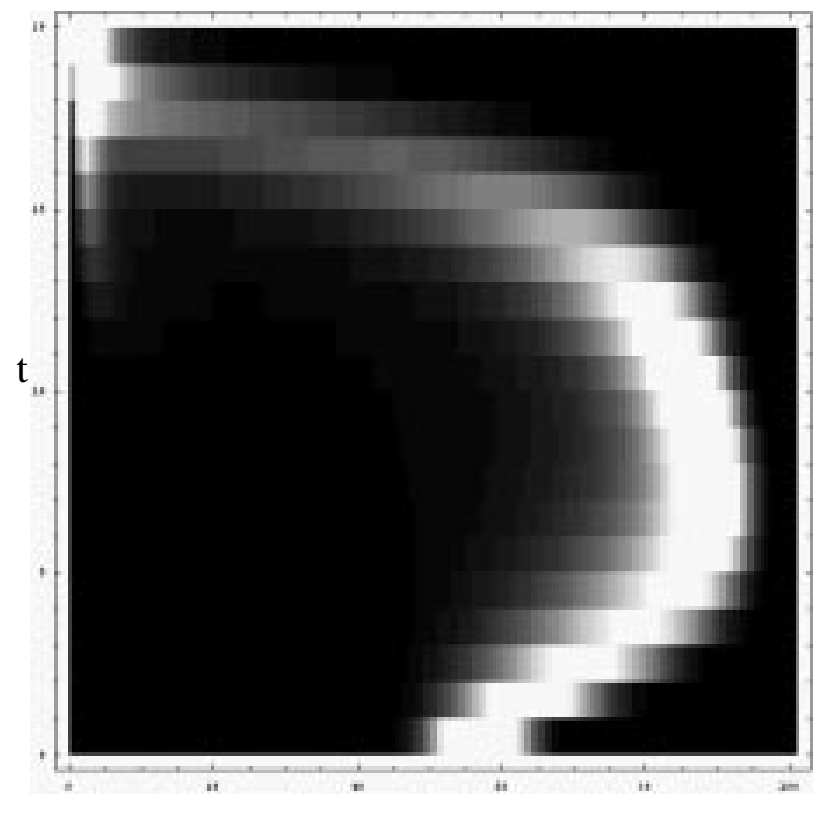

$\mathrm{X}$

fig. $4 \mathrm{~b}$ ) Density plot of scenario II ( $\left.\beta=1.5, \delta_{0}=0.25, r=-0.0005\right)$

Again we see a bias towards cooperative environments, now even more significant compared to the development sketched above. The emergence of large informal networks is now much faster and more distinctive. A higher technological intensity going hand in hand with a faster pace of technical progress is responsible for informal networks to become self- 
organizationally a strong attractor over a longer period of time. The exploration of extensive opportunities through the amalgamation of different technologies makes a cooperative spillover-oriented R\&D strategy attractive for several periods. Now, in scenario II, an informal network is dominant even if the preference function in the individual transition rates would already indicate defective behaviour on the firm's micro-level. Informal networks on the macro-level are a kind of an attraction field, which cannot be left without considerable efforts. Not before the preference function increases even more, a sudden but abrupt wheeling around towards the strategy of secrecy is to be observed. Figure 5 illustrates this abrupt change by depicting phase-portraits of selected periods.

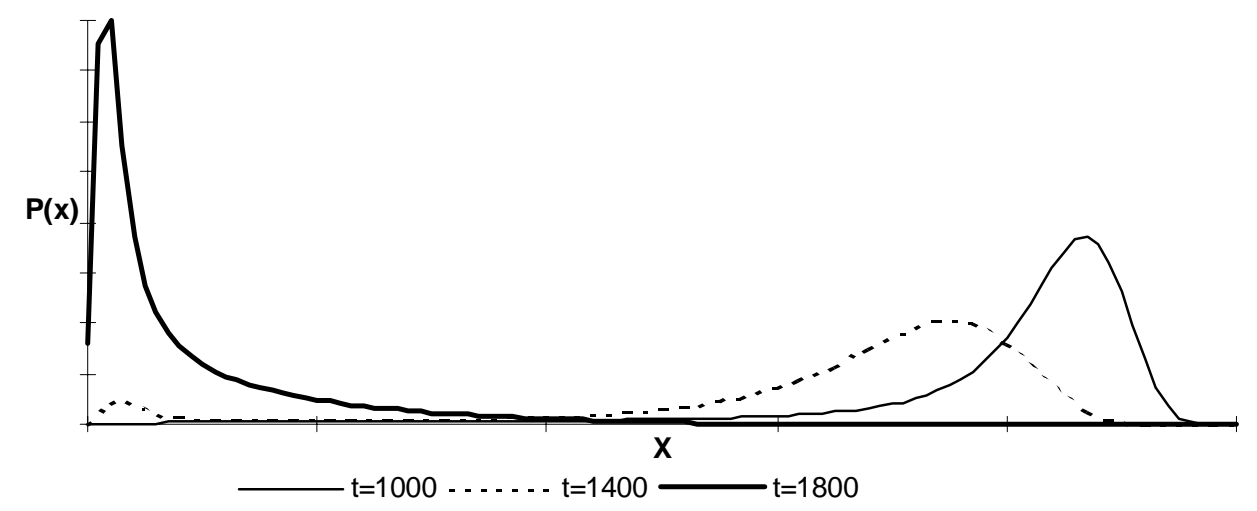

fig. 5: Phase portraits of selected periods

Despite the original preference for cooperation, we again find a phase transition in the evolution of informal networks in this scenario. However, only after about two thirds of the time horizon investigated, a small probability for non-cooperative environments begins to increase, even if first on a likewise low level - the probability distribution becomes bimodal. In the first instance this possibility of a non-cooperative solution is only a weak attractor which does not gain importance and influence before the final periods. Here, the decline in the individual preferences for cooperation reaches a critical threshold causing the probability of an informal network to decrease sharply.

In the context of industry-life-cycles the causes of this threshold effect can be seen in the shakeout of smaller cooperative firms at the final stage of the technological development. Thus, at the end of our simulated development we can just assume a few larger, but noncooperative firms in that industry, now also characterized by a larger degree of concentration. 


\section{Conclusions}

In a technological development characterized as a 'collective invention', cooperative environments can emerge via self-organization. The requirements of the modern innovation process demand new forms of industrial organization and the phenomenon of informal knowhow exchange is probably a very promising one ${ }^{15}$. Our model is able to demonstrate the possible evolution of an informal network, thereby not using traditional analytical tools with the criticised restrictive assumption of perfect rationality. The synergy in the evolution of an open system, where mutually reinforcing factors create dynamic effects under certain circumstances makes both possibilities, a cooperative and a non-cooperative environment probable. Which solution actually establishes cannot be predicted ex-ante and depends on small perturbations in the course of time. This open feature in the development of informal networks corresponds quite well to the indeterminacy, intrinsic to technological evolution.

However, the different solutions are dependent on the technological intensity. Especially in environments where technological factors play an outstanding role, a positive probability for the emergence and the absence of a network exists. These results correspond to observations in reality. Although technology is very important in some industries like pharmaceuticals and chemicals, these branches are quite self-sufficient with respect to $R \& D$, and the establishment of an informal network is less likely to occur. However, in other industries, such as semiconductors and aerospace, which are also technologically intensive, the phenomenon of informal networking can be observed more readily ${ }^{16}$.

Additionally, the results of our model can be interpreted in the light of emerging industries in a life-cycle context. In early formative periods of new technological systems by definition almost no dominant design and standards exist. These periods are characterized by high technological uncertainty. Thus, until a dominant design emerges, there are advantageous conditions for the establishment of large informal networks and cooperative environments. In later periods when economies of scale and standardization become more and more important cooperatitive attitudes diminish ${ }^{17}$. This indicates a cyclical feature of informal networking with respect to the age of technological paradigms. Moreover, our results suggest that

\footnotetext{
${ }^{15}$ Clark and Juma (1987, p. 170) state: "Coping with non-linear situations requires effective information flows and systemic organization in which networking plays a significant role."

16 See Eliasson (1995).
} 
significant spillover pools can be found in industries characterized by a large technological intensity in even more mature phases of the development: here informal networks become a dominant attractor despite the intuitive expectation of a dominance of a strategy aiming at keeping new know-how secret.

The last point worth mentioning concerns methodological issues. With the integration of time patterns a first step is done to weaken the reproach often made to synergetics to model in fact development processes, but thereby not allowing the individual transition rates to develop. Of course, the time patterns integrated here, are of an exogenous nature, and an endogenous time pattern is yet to be included. This will be on our future research agenda.

${ }^{17}$ See Dodgson, M. (1993) and Freeman, C. (1991). 


\section{References}

Chesnais, F. (1996), Technological Agreements, networks, and selected Issues in Economic Theory: Coombs, R. et al. (eds.), Technological Collaboration in Industrial Innovation, Edward Elgar, London.

Clark, N., Juma, C. (1987), Long Run Economics - An Evolutionary Approach to Economic Growth, Pinter Publishers, London.

Coombs, R. (1988), Technological Opportunities and Industrial Organization, in: Dosi, G. et al. (eds.), Technical Change and Economic Theory, Pinter Publishers London.

Dahmèn, E.(1989), Development Blocks in Industrial Economics, in: Carlsson, B. (Hrsg.), Industrial Dynamics, Kluwer Academic Publishers, Dodrecht.

Dodgson, M. (1993), Technology Collaboration in Industry: Strategy, Policy and Internationalization in Innovation, Routledge, London and New York.

Dodgson, M. (1996), Learning, Trust and Inter-Firm Linkages: Some theoretical Associations, in: Coombs, R. et al. (eds.), Technological Collaboration in Industrial Innovation, Edward Elgar, London.

Dodgson, M.(1994), Technological Collaboration and Innovation, in: Dodgson, M., Rothwell, R. (eds.), The Handbook of Industrial Innovation, Edward Elgar, London, 1994.

Dosi, G. (1988), Sources, Procedures, and Microeconomic Effects of Innovation, Journal of Economic Literature, Vol. 24, 1120-1171.

Eger, T., Weise, P. (1995), Die Evolution von Normen aus Unruhen: Ein synergetisches Modell, In: Ökonomie und Gesellschaft, Jahrbuch 11, Markt, Norm und Moral, Frankfurt Campus, 192-209.

Eliasson, G. (1995), General Purpose Technologies, Industrial Competence and Economic Growth - With special Emphasis on the Diffusion of Advanced Methods of Integrated Production, Working Paper, Royal Institute of Technology, Stockholm.

Erdmann, G. (1993), Elemente einer evolutorischen Innovationstheorie, J.C.B. Mohr, Tübingen.

Foray, D. (1995), The Economics of Intellectual Property Rights and Systems of Innovation: The Persistence of National Practices vs. the New Global Model of Innovation, in: Hagedoorn, J. (ed.), Technical Change and the World Economy, Edward Elgar.

Freeman, C. (1991), Networks of Innovators, A Synthesis of Research Issues, Research Policy, Vol. 20, 499-514.

Gierer, G. (1981), Socioeconomic Inequalities: Effects of Self-Enhancement, Depletion and Redistribution, Jahrbücher für Nationalökonomie und Statistik, Vol. 196, 309-331.

Granstrand, O., Sjolander, S. (1990), Managing Innovation in Multi-Technology Corporations, Research Policy, Vol. 19, 35-60.

Joly, P. B., Mangematin, V. (1995), Les acteurs sont-ils solubles dans les reseaux?, Economies et Societées, Serié Dynamiques Technologique et Organization, no. 2, pp. $17-50$.

Klepper, S. (1997), Industry Life Cycles, Industrial and Corporate Change, Vol. 6, 145-82.

Klepper, S., Graddy, E. (1990), The Evolution of New Industries and the Determinants of Market Structure, Rand Journal of Economics, Vol. 21, 27-44. 
Klepper, S., Simonis, K.L., (1997), The Making of an Oligopoly: Firm Survival and Technological Change in the Evolution of the U.S. Tire Industry, Papier vorgestellt am Workshop: Economic Evolution, Learning and Complexity, Augsburg, May 1997.

Kodama, F. (1986), Technology Fusion and the New R\&D, Harvard Business Review, JulyAugust, 1992, 70-78.

Mody, A. (1993), Learning through Alliances, Journal of Economic Behaviour and Organization, Vol. 20, 151-170.

Mokyr, J. (1990), The Lever of Riches, Oxford University Press, New York.

Nelson, R. R. (1988), Institutions supporting Technical Change in the US, in: : Dosi, G. et al. (eds.), Technical Change and Economic Theory, Pinter Publishers London.

Pyka, A. (1997), Informal Networking, Technovation, Vol. 17, 207-220.

Schumpeter, J. A. (1912), Theorie der wirtschaftlichen Entwicklung, Duncker\&Humblot, Berlin, 8. Auflage, 1993.

Schumpeter, J. A. (1942), Capitalism, Socialism and Democracy, London, Unwin.

Silverberg, G. (1988), Modelling Economic Dynamics and Technical Change: Mathematical Approaches to Self-Organization and Evolution, in: Dosi, G. et al. (eds.), Technical Change and Economic Theory, Pinter Publishers, London and New York.

Utterback, J. (1987), Innnovation and Industrial Evolution in Manufacturing Industries, in: Guile, B.R., Brooks, H. (eds.), Technology and Global Industry - Companies and Nation in the World Economy, National Academic Press, Washington D.C.

Von Hippel, E. (1989), Cooperation between Rivals: Informal Know-how Trading, in: Carlsson, B. (ed.), Industrial Dynamics, Kluwer Academic Publishers.

Weidlich, W., Haag, G. (1983), Concepts and Models of a Quantitative Sociology, Springer Berlin.

Winter, S. G. (1989), Patents in Complex Contexts: Incentives and Effectiveness, in: Weil, V. et al. (eds.), Owning Scientific and Technical Information, Rutgers University Press.

Witt, U. (1997), Imagination and Leadership - The Neglected Dimension of an Evolutionary Theory of the Firm, Papers on Economics and Evolution, \#9605.

Zuscovitch, E., Justman, M. (1995), Networks, Sustainable Differentiation, and Economic Development, in: Batten, D., Casti, J., Thord, R. (eds.), Networks in Action, Economics and Human Knowlege, Springer Verlag, Berlin. 